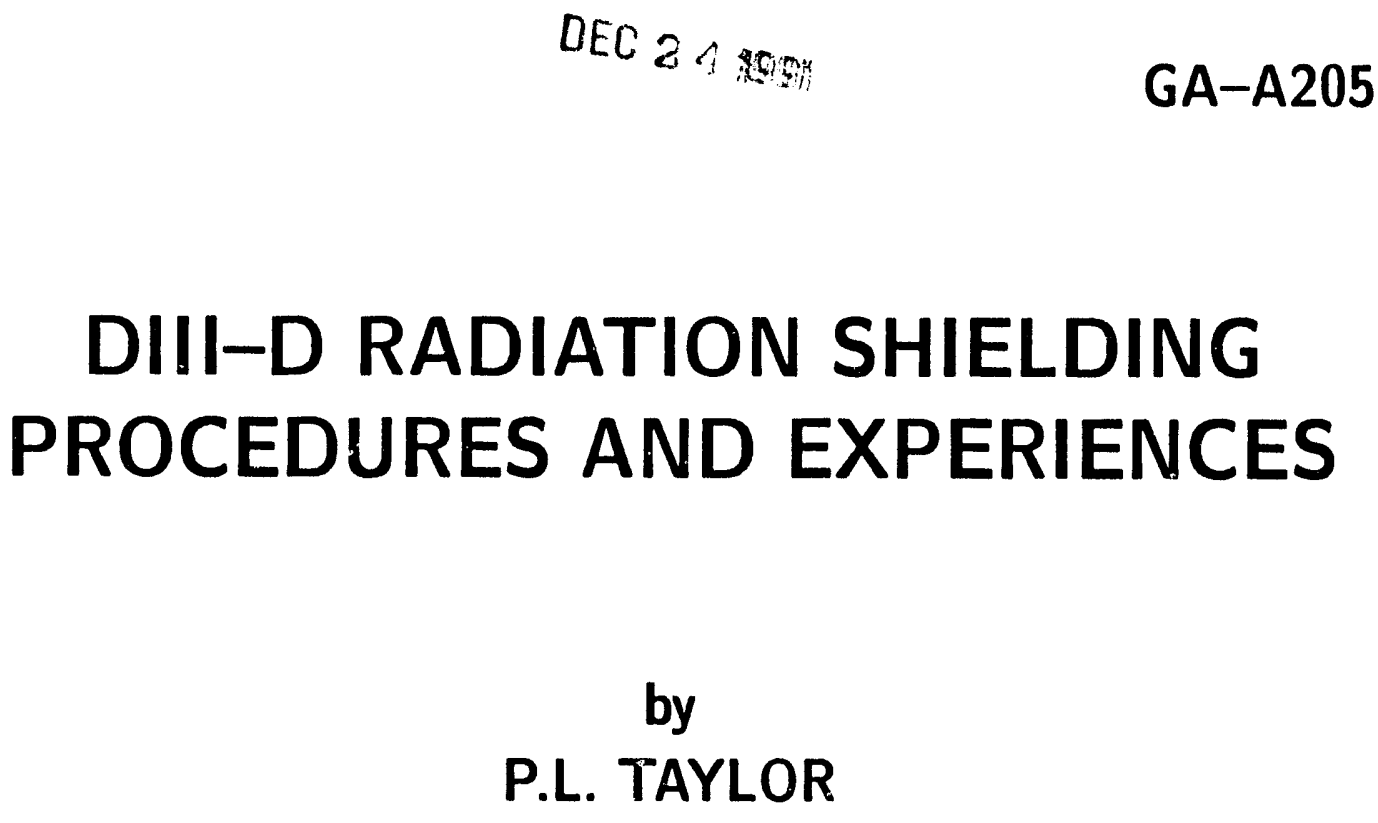

NOVEMBER 1991

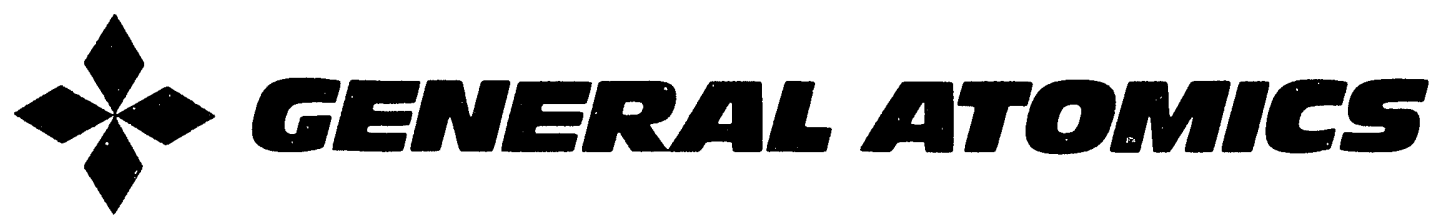

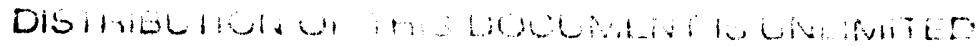




\section{DISCLAIMER}

This report was prepared as an account of work sponsored by an agency of the United States Government. Neither the United States Government nor any agency thereof, nor any of their employees, makes any warranty, express or implied, or assumes any legal liability or responsibility for the accuracy, completeness, or usefulness of any information, apparatus, product, or process disclosed, or represents that its use would not infringe privately owned rights. Reference herein to any specific commercial product, process, or service by trade name, trademark, manufacturer, or otherwise, does not necessarily constitute or imply its endorsement, recommendation, or favoring by the United States Government or any agency thereof. The views and opinions of authors expressed herein do not necessarily state or reflect those of the United States Government or any agency thereof. 


\title{
DIII-D RADIATION SHIELDING PROCEDURES AND EXPERIENCES
}

\author{
by \\ P.L. TAYLOR
}

This is a preprint of a paper to be presented at the 14th Symposium on Fusion Engineering, September 30-October 3, 1991, San Diego, California, and to be printed in the Proceedings.

\author{
Work supported by \\ Department of Energy \\ Contract DE-AC03-89ER51114
}

GENERAL ATOMICS PROJECT 3466

NOVEMBER 1991

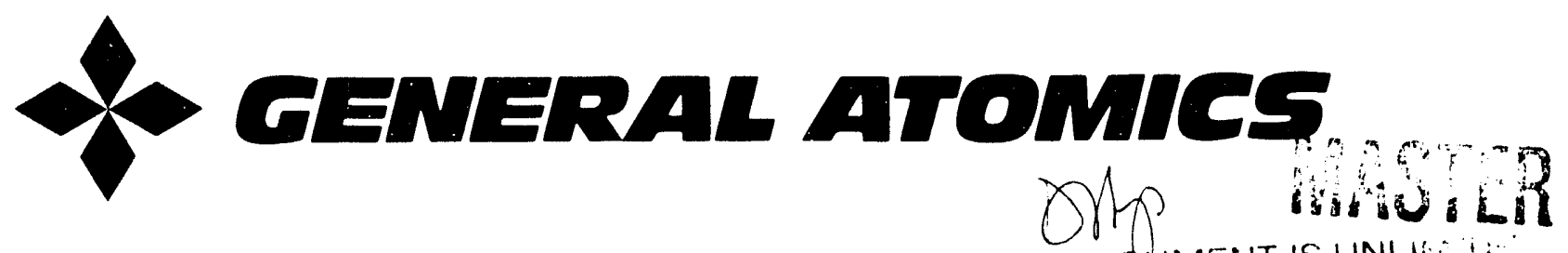




\title{
DIII-D RADIATION SHIELDING PROCEDURES AND EXPERIENCES
}

\author{
P.L. Taylor \\ General Atomics \\ P.0. Box 85608 \\ San Diego, California 92186-9784
}

\begin{abstract}
The DIII-D tokamak operates with a neutron radiation shield to allow enhanced plasma operations with increased neutron production while minimizing the site boundary dose level. Neutron rates as high as $4 \times 10^{15}$ neutrons/s and total neutron production as high as $4 \times 10^{15}$ neutrons per shot are obtained while maintaining the site dose below the DOE administrative level of 20 mrem per year; a much more restrictive level than the State of California radiation limits. The radiation shielding has increased by a factor of 300 over the preshield value and is in agreement with the design calculation. The maximum site neutron dose since installation of the shield has been less than 0.03 mrem for a shot and less than $0.4 \mathrm{mrem}$ for a day. The site neutron and gamma dose are monitored continuously during operations by a PC-based computer system that provides the means of measuring the low dose levels that occur during a shot by including postshot background subtraction. The neutron and gamma dose are measured and archived by shot, hour, and day in a database. Activation of the machine after a run day and during vessel entries is monitored and the activated nuclides have been determined. A radiation monitoring program and procedures are used to control the exposures to facility personnel and the exposure at the site boundary.
\end{abstract}

\section{Introduction}

The DIII-D tokamak is a large, D-shaped, toroidal confinement device with major radius $1.67 \mathrm{~m}$ and minor radius $0.67 \mathrm{~m}$ [1]. The tokamak facility completed an upgrade in the spring of 1989 which included additional radiation shielding $[2,3]$ to allow more extensive operation with neutron generating deuterium beams and deuterium plasmas. The previous shielding, designed primarily as a gamma shield, consisted of $63 \mathrm{~cm}$ thick concrete walls to a height $3.1 \mathrm{~m}$ above the vessel midplane ( $\sim 1.7 \mathrm{~m}$ above the top of the plasma vessel). The additional neutron shield [4] extended the concrete walls to a shielded roof consisting of a movable section for crane access and a fixed section. The neutron shield walls are $30 \mathrm{~cm}$ of polyboron material while the roof is $36 \mathrm{~cm}$ of a water based boronated gel.

\section{Sources of Radiation}

There are two major sources of radiation from DIII-D. The first is the instantaneous neutron and gamma radiation that occurs during the 1 to $2 \mathrm{~s}$ high power part of a typically $5 \mathrm{~s}$ shot; this radiation determines the site boundary dose and the employee exposure. Neutrons dominate the site radiation; the gamma dose is typically 30 to $50 \%$ of the neutron dose and is due to neutron interactions with the shield. The second source of radiation is the long term gamma radiation from neutron activation of the machine and surrounding material; this radiation also determines employee exposure and necessitates control of activated material.

The neutrons in a shot come mainly from two sources; the $D-D$ thermonuclear reactions in the deuterium plasma and the $D-D$ beam target reactions when deuterium neutral beams are injected into the deuterium plasma. The dominant dependence of the neutron rate is on the ital energy stored in the plasma (Fig. 1) and the empirical scaling for the beam-target neutrons is the stored energy to the three-halves power while the thermonuclear reactions scale as the stored energy cubed. Prior to the additional shielding, only a few high neutron production shots with deuterium beams were obtained and the total integrated neutron production was $\sim 6 \times 10^{15}$ neutrons. Neutron rates of $4 \times 10^{15}$ neutrons/s have now been obtained and the total neutron production is $\sim 2 \times 10^{18}$ neutrons (thru Dec. 1990). This neutron production is below the levels where radiation damage to structural materials begins but electronic and optical components near the machine may be near the threshold for damage. Metals and G-10 have a damage threshold at neutron fluences of $\sim 10^{18}$ reutrons $/ \mathrm{cm}^{2}$ while electronics and optical components used ir, diagnostics have a threshold of $\sim 10^{14}-10^{18}$ neutrons $/ \mathrm{cm}^{2}[5]$

The second source of radiation, from the neutron activation of the machine, is dominated by short-lived nuclides and drops by approximately two orders of magnitude in one day and four orders of magnitude in one week.

\section{Radiation Limits}

A key goal of DIII-D operations is the minimization of the exposure to radiation of the general public and of employees. The allowed radiation exposures are set by the State of California limits and the much rnore restrictive U.S. Department of Energy (DOE) administrative guidelines governing DIII-D operation. Table 1 gives the dose limits for unrestricted areas (site boundary, general public) and restricted areas (employees).

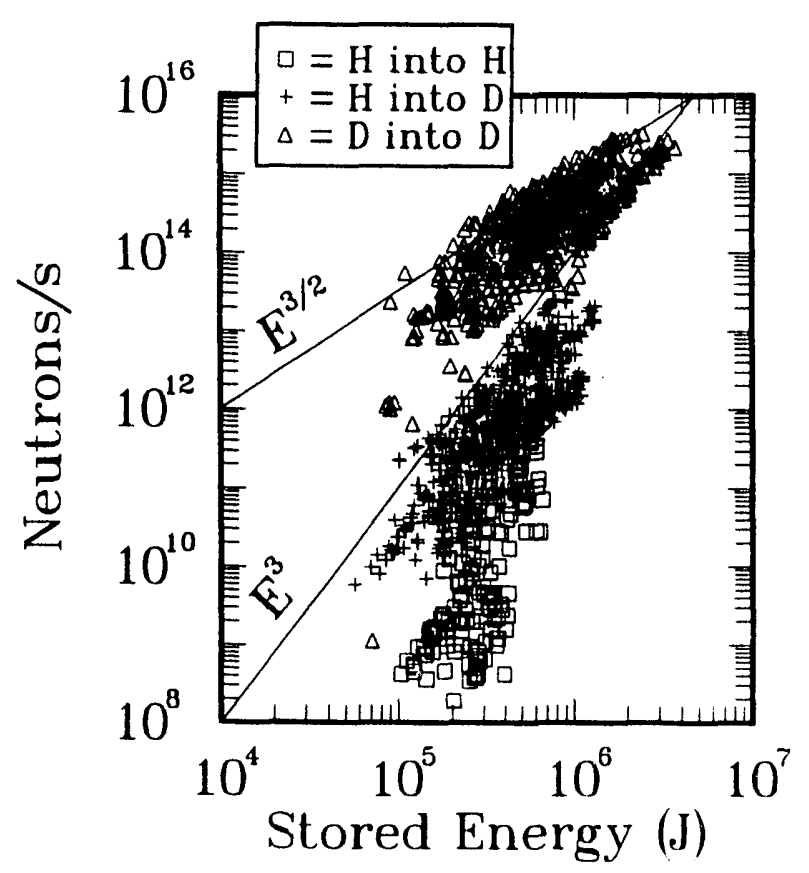

Fig. 1. Neutron rate versus plasma stored energy for neutral hydrogen beams injected into hydrogen plasmas, hydrogen beams into deuterium plasmas, and deuterium beams into deuterium plasmas. 


\begin{tabular}{|l|c|c|c|}
\hline \multicolumn{4}{|c|}{ Table 1 RADIATION DOSE LEVELS } \\
\hline & $\begin{array}{c}\text { California } \\
\text { Regulation } \\
\text { Limits }\end{array}$ & $\begin{array}{c}\text { DOE } \\
\text { Guidelines }\end{array}$ & $\begin{array}{c}\text { DIII-D } \\
\text { Procedures }\end{array}$ \\
\hline $\begin{array}{l}\text { Unrestricted Areas } \\
\text { (Site Boundary) }\end{array}$ & $\begin{array}{c}500 \text { mrem in } \\
\text { any year } \\
100 \text { mrem in } \\
\text { any } 7 \text { days } \\
2 \text { mrem in } \\
\text { any hour }\end{array}$ & $\begin{array}{c}20 \text { mrem/ } \\
\text { year } \\
\text { mrem/ } \\
\text { quarter }\end{array}$ & $\begin{array}{c}20 \text { mrem/ } \\
\text { year } \\
5 \text { mrem/ } \\
\text { quarter }\end{array}$ \\
\hline Restricted Areas & $\begin{array}{c}1250 \text { mrem/ } \\
\text { quarter }\end{array}$ & & $\begin{array}{c}300 \text { mrem/ } \\
\text { quarter } \\
100 \text { mrem/ } \\
\text { week } \\
25 \text { mrem/ } \\
\text { day } /\end{array}$ \\
\hline
\end{tabular}

Based on the DOE guidelines for the site boundary limit and the California regulations, the DIII-D procedures for limits to employees were developed and are a factor of four more restrictive than the state requirements. During operations, limited access to high radiation areas, the spatial falloff of the radiation, and DIII-D procedures result in employee exposures far below the regulatory limits. The dominant limits for DIII-D operations are the site boundary limits of $20 \mathrm{mrem} / \mathrm{year}$ and $2 \mathrm{mrem} / \mathrm{h}$.

An experimental plan sets the radiation limits for each day of operation. All daily experimental tasks are described by a mini-proposal which includes a request for the anticipated radiation level. A planning meeting approves the experiments for a typical two-week run period and sets the allowed radiation levels for each day.

Procedures have been developed for controlling operations, handling activated material, and working in areas where radiation due to activation exists. These procedures ensure that the radiation limits for personnel and for the site boundary are not exceeded; that all personnel are properly trained and their radiation dose monitored; that all radiation producing activities are monitored; and that all possibly activated material is checked for radiation and controlled if activated. In particular, working inside the DIII-D vessel also requires monitoring for tritium exposure and airborne particulate contamination. To drive the tritium out of the carbon tiles and other inside components the vessel is routinely baked to $350^{\circ} \mathrm{C}$ prior to venting. During initial purging of the vessel with air the exhaust is passed through a HEPA filter so that no airborne particulate contamination is released. Samples taken at the beginning of each vessel vent for airborne particulate contamination have been below the limit of $3 \times 10^{-9} \mu \mathrm{Ci} / \mathrm{ml}$ and wipe samples taken for removable contamination have been below $25 \mathrm{DPM} / 100 \mathrm{~cm}^{2}$ (an internal General Atomics limit). Due to the low levels of tritium that may be present urinalysis samples from workers in the vessel have been used to check for tritium exposure and have shown insignificant amounts.

\section{Radiation Monitoring}

Neutron and gamma radiation are monitored by area film badges throughout the facility and along the site boundary. Thermoluminescent Detectors (TLD) are also used to monitor gamma radiation along the site boundary due to their higher sensitivity. Personnel dosimeters (film/TLD) are used to document each individual's exposure to neutron and gamma radiation. All badges are read quarterly to determine the accumulated dose.
Due to the low level of radiation produced, which is below the sensitivity of the film badges, the neutron and gamma radiation are also monitored in realtime during experimental operations with NRC Industries neutron detectors and Ludlum gamma scintillator detectors. Two permanent stations at the highest radiation point on the site boundary $(83 \mathrm{~m}$ from the machine) and at the control room ( $30 \mathrm{~m}$ from the machine) are monitored along with occasional portable locations for surveys of the facility and the site boundary. All the realtime detectors have their signals collected by a PC-based computer that records the radiation by shot and by hour. Due to the low levels produced, determining the radiation produced by a shot requires subtracting a background accumulation after the shot. The computer monitors the radiation and is interlocked with the shot control computer which checks before each shot to see that the radiation monitoring program is running and that the site limits for that day and hour have not been exceeded. Figures 2 and 3 show a histogram of the radiation produced on a shot and a histogram of the daily site boundary radiation for operations during 1990. The average radiation is well below the maximums of 0.025 mrem for a shot and $0.4 \mathrm{mrem}$ for a day. The total site radiation by calendar quarter (Fig. 4) has been less since installation of the neutron shield.

\section{Shielding Factor}

The shielding improvement, due to the additional neutron shielding, is quantified in terms of the shielding factor. This factor is defined as the ratio of the radiation dose at the site boundary before the new shielding was installed to the radiation dose at the site boundary after the new shielding was installed for the same total number of plasma neutrons.

The shielding factor measurement is difficult due to two factors. First, low levels of radiation must be measured due to the low dose ( 5 mrem per quarter) allowed at the site boundary. Typically, neutron generating shots produce only a couple of $\mu \mathrm{rem}$ at the site boundary. Second, comparisons before and after the shield construction rely on the diagnostic measuring the number of neutrons generated in the plasma to have maintained calibration over a long time interval (months to years).

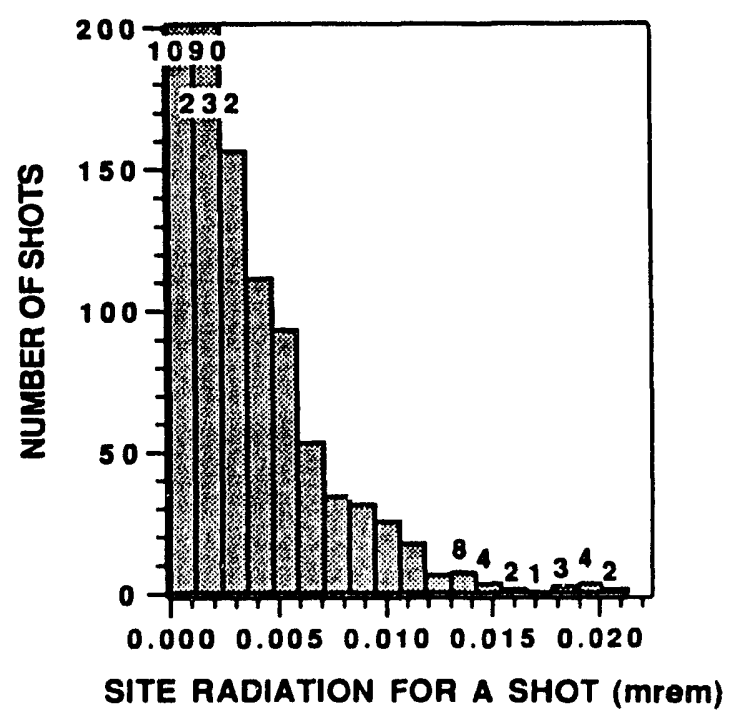

Fig. 2. Histogram of the total site radiation (neutron and gamma) produced by a shot, for all 1990 shots (2024 shots). 


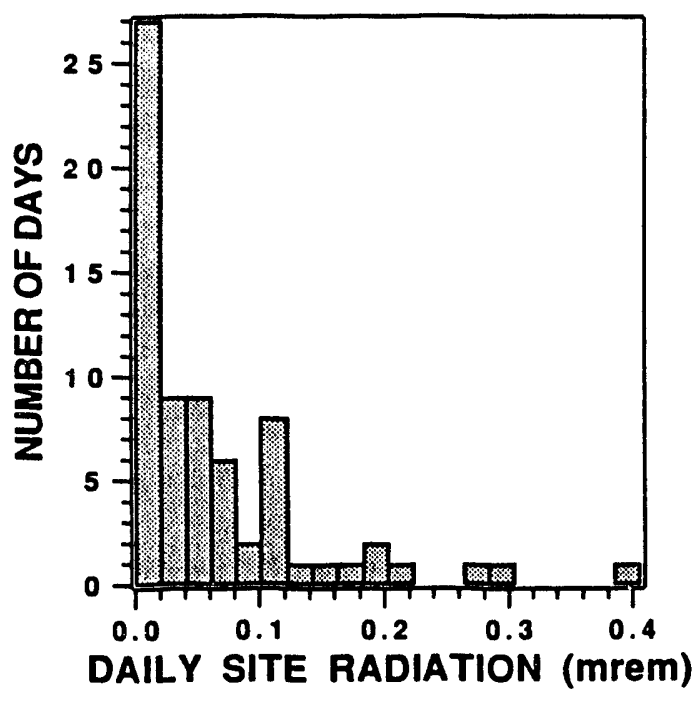

Fig. 3. Histogram of the total daily site radiation for 1990.

The instruments used in the measurements include the site boundary neutron and gamma detectors for the site radiation dose, and an array of ${ }^{3} \mathrm{He}$ and $\mathrm{BF}_{3}$ proportional detector tubes with moderators in the machine torus hall for the neutron rate and total plasma neutrons. The neutron detecior for the site dose measurement is an instrument with a response corresponding to the human body, and is recalibrated at the factory at six-month intervals with an accuracy of $\pm 20 \%$. The ${ }^{3} \mathrm{He}$ and $\mathrm{BF}_{3}$ detector arrays are calibrated in situ using a ${ }^{252} \mathrm{Cf}$ neutron source in the machine during a vent and have a typical accuracy of $\pm 15 \%[6]$. Their most recent calibration was in January 1990. The ${ }^{3} \mathrm{He}$ and $B F_{3}$ detectors are the most sensitive to $a$ calibration drift due to the long interval between calibrations.

The shielding factor was measured in two ways. Since the site boundary radiation dose is directly proportional to the number of neutrons generated in the plasma, one method of measuring the shielding factor is to compare the site boundary radiation dose generated per plasma neutron before and after the shield installation. The original shielding of the concrete walls alone is given as ratio of the site boundary neutron radiation dose in mrem to the number of ne.Atrons generated in the plasma: $1.3 \times 10^{-15} \mathrm{mrem} /$ neutron $[2,3]$. Figure 5 shows the results of a set of shots from operation during 1990 where the net site neutron dose and the total number of plasma neutrons generated on a shot are compared. Summing the data for all these shots gives a total site neutron dose of $0.69 \mathrm{mrem}$ and a total neutron production of $1.9 \times 10^{17}$ neutrons; or $3.6 \times 10^{-18} \mathrm{mrem} /$ neutron. A least squares fit to the data in Fig. 5 gives a similar result: $3.7 \times$ $10^{-18} \mathrm{mrem} /$ neutron.] Ratioing these factors gives a shielding factor of 360 .

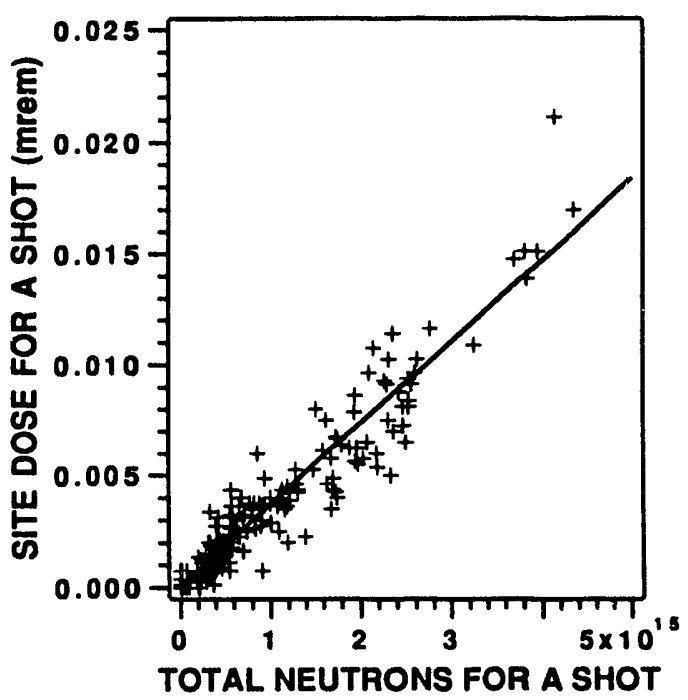

Fig. 5. Site neutron dose versus the total neutron production for the shot for 199 shots in 1990. A fitted line is also shown.

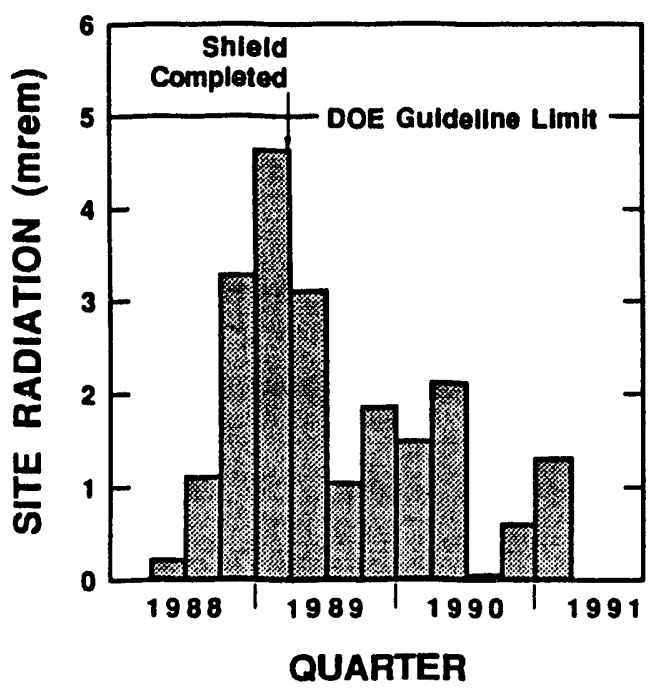

Fig. 4. Total site radiation (neutron and gamma) by calendar quarter. Also shown is the DOE administrative guideline of $5 \mathrm{mrem}$ per quarter and the time when the additional radiation shield was completed.
Another method of obtaining the shielding factor which does not rely on the absolute calibration of the pit neutron detectors is to measure the site radiation to plasma neutron ratio with the shielding roof off and with the shielding roof on and take the ratio of the two numbers. This gives a lower limit to the shielding factor. The neutron dose at the site boundary is dominated by "skyshine" [1] (the scattering of neutrons down to ground level by air molecules) when the roof is off. These measurements were performed on the same day which cancels any change in the plasma neutron detector calibration over time. With the roof off, the site dose limit restricts the number of shots. On the same day, two shots were taken with the roof off and gave $4.7 \times 10^{-15} \mathrm{mrem} /$ neutron, while with the roof on $1.4 \times 10^{-17} \mathrm{mrem} /$ neutron was measured; giving a shielding factor of 330 . (Note, the site dose per neutron obtained here cannot be compared to that obtained in the first calculation due to an adjustment of the neutron measuring diagnostic that changed the absolute calibration.)

Within the accuracy of the measurements, the shielding factor is in agreement with the factor of 300 predicted by calculations $[2,3]$. 


\section{Activation}

A gamma survey of the radiation due to activation outside the machine after an operations day found the activated nuclides listed in Table 2.

Table 2

\begin{tabular}{llrll}
\hline Nuclide & Reaction & Half Life & Source \\
\hline${ }^{38} \mathrm{Cl}$ & ${ }^{137} \mathrm{Cl}(n, \gamma){ }^{38} \mathrm{Cl}$ & $37.0 \mathrm{~min}$ & Concrete $\mathrm{H}_{2} 0$ \\
${ }^{65} \mathrm{Ni}$ & ${ }^{65} \mathrm{Cu}(n, \mathrm{p}){ }^{65} \mathrm{Ni}$ & $2.65 \mathrm{~h}$ & Coils \\
${ }^{56} \mathrm{Mn}$ & ${ }^{55} \mathrm{Mn}(n, \gamma){ }^{56} \mathrm{Mn}$ & $2.57 \mathrm{~h}$ & Inconel \\
${ }^{56} \mathrm{Mn}$ & ${ }^{56} \mathrm{Fe}(n, \mathrm{p}){ }^{56} \mathrm{Mn}$ & 2.6 & $\mathrm{~h}$ & Inconel \\
${ }^{99} \mathrm{Tc}$ & ${ }^{98} \mathrm{Tc}(n, \gamma){ }^{99} \mathrm{Tc}$ & 6.0 & $\mathrm{~h}$ & Inconel \\
${ }^{64} \mathrm{Cu}$ & ${ }^{63} \mathrm{Cu}(n, \gamma){ }^{64} \mathrm{Cu}$ & 12.8 & $\mathrm{~h}$ & Coils \\
${ }^{64} \mathrm{Cu}$ & ${ }^{65} \mathrm{Cu}(n, 2 n){ }^{64} \mathrm{Cu}$ & 12.8 & $\mathrm{~h}$ & Coils \\
${ }^{24} \mathrm{Na}$ & ${ }^{24} \mathrm{Mg}(n, \mathrm{p}){ }^{24} \mathrm{Na}$ & 15.0 & $\mathrm{~h}$ & Fiberglass \\
${ }^{24} \mathrm{Na}$ & ${ }^{23} \mathrm{Na}(n, \gamma){ }^{24} \mathrm{Na}$ & 15.0 & $\mathrm{~h}$ & Stainless \\
${ }^{187} \mathrm{~W}$ & ${ }^{186} \mathrm{~W}(n, \gamma){ }^{187} \mathrm{~W}$ & 24.1 & $\mathrm{~h}$ & Stainless \\
${ }^{76} \mathrm{As}$ & ${ }^{75} \mathrm{As}(n, \gamma){ }^{76} \mathrm{As}$ & 26.0 & $\mathrm{~h}$ & Plywood \\
${ }^{82} \mathrm{Br}$ & ${ }^{81} \mathrm{Br}(n, \gamma){ }^{82} \mathrm{Br}$ & 35.0 & $\mathrm{~h}$ & Fiberglass \\
${ }^{99} \mathrm{Mo}$ & ${ }^{88} \mathrm{Mo}(n, \gamma){ }^{99} \mathrm{Mo}$ & 67.0 & h & Inconel \\
${ }^{122} \mathrm{Sb}$ & ${ }^{121} \mathrm{Sb}(n, \gamma){ }^{122} \mathrm{Sb}$ & 2.7 & day & Lead \\
${ }^{51} \mathrm{Cr}$ & ${ }^{54} \mathrm{Fe}(n, \alpha){ }^{51} \mathrm{Cr}$ & 27.7 & day & Inconel \\
${ }^{51} \mathrm{Cr}$ & ${ }^{52} \mathrm{Cr}(n, 2 n){ }^{51} \mathrm{Cr}$ & 27.7 & day & Inconel \\
${ }^{124} \mathrm{Sb}$ & ${ }^{123} \mathrm{Sb}(n, \gamma){ }^{124} \mathrm{Sb}$ & 60.0 & day & Lead \\
${ }^{58} \mathrm{Co}$ & ${ }^{58} \mathrm{Ni}(n, \mathrm{p}){ }^{58} \mathrm{Co}$ & 70.0 & day & Inconel \\
& & & & \\
\hline
\end{tabular}

The maximum dose rate due to activation is next to the vessel and has reached $36 \mathrm{mrem} / \mathrm{h}$ after a high neutron generating day. The dose rate has an initial half-life of approximately $5 \mathrm{~h}$ and after $24 \mathrm{~h}$ the half-life is approximately $20 \mathrm{~h}$. During vessel vents for entry, the dose rate inside the vessel (Fig. 6) is typically a couple of $\mathrm{mrem} / \mathrm{h}$ and decays with a 62 day half-life typical of the activated nuclides found in the inconel vessel.

\section{Summary}

The improvement in the radiation shielding achieved by the newly constructed shield wall is in agreement with the calculated shielding factor. The measured shielding factor was 330 to $\mathbf{3 6 0}$ while the calculated factor was 300 . Procedures have been developed to monitor the increased radiation levels, control access, and monitor activated material. The additional neutron radiation shield has allowed important high power and higher temperature fusion experiments to be carried out while minimizing the radiation exposure to the public and the employees.

\section{Acknowledgment}

The author gratefully acknowledges the assistance of the GA Health Physics group and DIII-D operations group.

This work was sponsored by the U.S. Department of Energy under Contract No. DE-AC03-89ER51114.

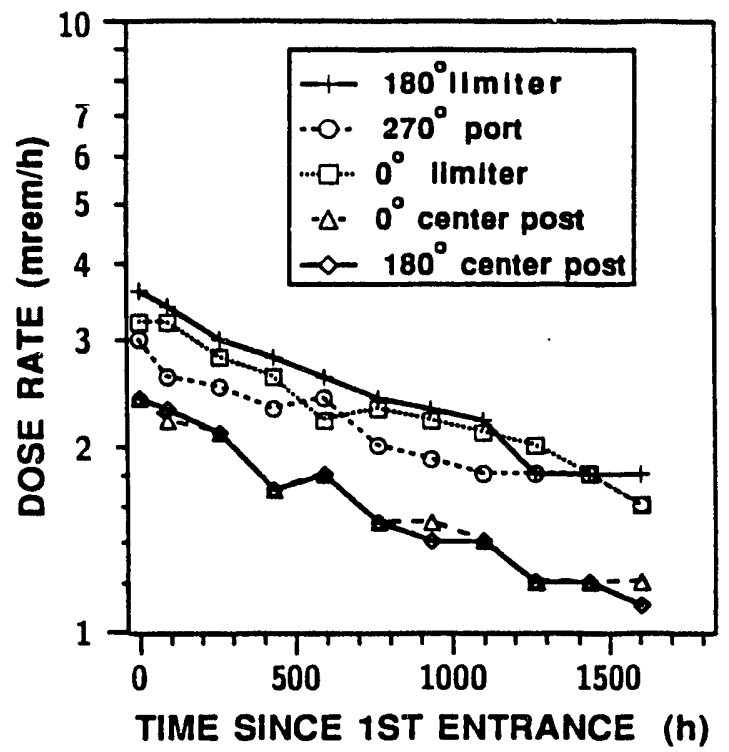

Fig. 6. Dose rate inside the DIII-D vessel from the time of the first entry of the June 1990 vent. The radiation decays with a net half-life of approximately 62 days.

\section{References}

[1] Colleraine, A.P., et al., "Latest Results from DIII-D and their Implications for Future Devices," Fusion Technology (Proc. 9th Topical Meeting on the Technology of Fusion Energy, Oak Brook, 1990) ANS.

[2] "Radiation Aspects of DIII-D," J. Kim and J.L. Luxon (eds.), General Atomics Report GA-C19537 (February 1989).

[3] Kim, J., et al., "Radiation Shielding Analysis for DIII-D," Proc. 13th Symp. Fusion Erig., Knoxville, 1989; Vol. 2, IEEE (1990) 869.

[4] Anderson, P.M., etal., "Neutron Shielding System for DIII-D Research Facility," Proc. 13th Symp. Fusion Eng., Knoxville, 1989; Vol. 2, IEEE (1990) 1340.

[5] Baur, J., etal., "Radiation Hardening of Diagnostics for Fusion Reactors," General Atomics Report GA-A16614 (December 1981).

[6] Taylor, P.L., "Neutron Detector Calibration and Neutron Measurement Results from the DIII-D Tokamak," Bull. of Am. Phys. Soc. 35 (1990) 1973. 

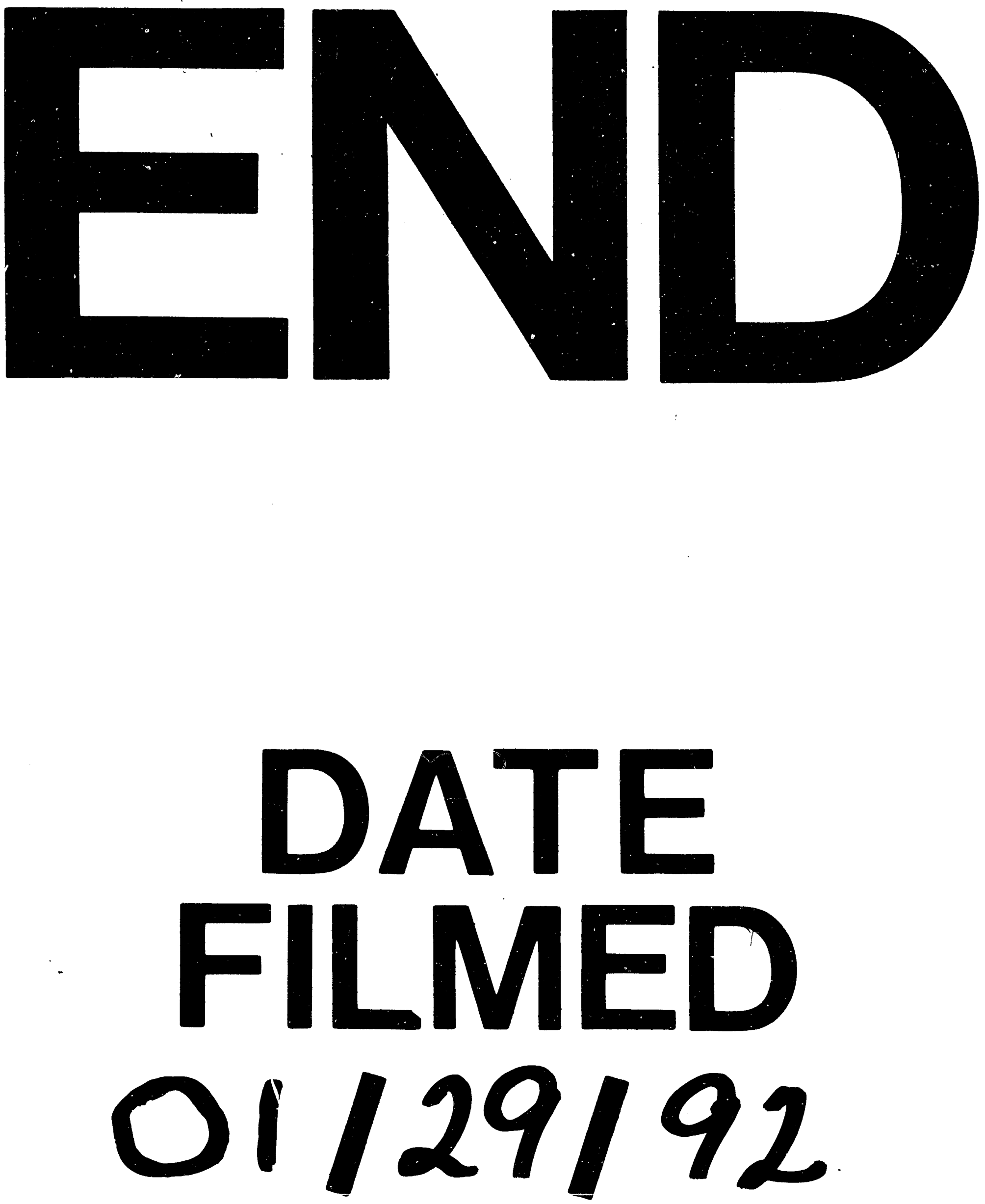
